\title{
Noktalama İşaretlerinin Öğretimine İlişkin Öğretmen Görüşleri*
}

\author{
Teacher Views on Teaching Punctuation Marks
}

\author{
Mehmet KURUDAYIOĞLU**, Onur DÖLEK***
}

\begin{abstract}
Öz: Araştırmada noktalama işaretlerinin öğretim süreci ile ilgili Türkçe öğretmenlerinin görüşlerine başvurulmuştur. Bu görüşlerin noktalama öğretimine yönelik geliştirilebilecek yöntem, teknik, stratejiler ve alınacak önlemler konusunda önemli olabileceği ve dolaylı yoldan temel dil becerilerinin geliştirilmesine katkı sağlayabileceği düşünülmüştür. Bu bağlamda araştırmanın amacı noktalama işaretlerinin öğretilmesi sürecine ilişkin Türkçe öğretmenlerinin ne tür görüş ve yaklaşımlara sahip olduğunu belirlemektir. Araştırmanın çalışma grubunu otuz sekiz Türkçe öğretmeni oluşturmaktadır. Araştırmada altı açık uçlu sorudan oluşan yarı yapılandırılmış görüşme formundan yararlanılmıştır. Araştırmadan elde edilen verilerin çözümlenmesinde betimsel çözümleme yöntemi kullanılmıştır. Araştırmada Türkçe öğretmenlerinin noktalama işaretlerinin temel dil becerilerindeki önem ve işlevinin büyük oranda farkında oldukları, noktalama işaretlerinin öğretiminde düz anlatım ve soru-cevap yöntemlerini daha çok yeğledikleri sonuçlarına ulaşılmıştır. Araştırmadan elde edilen diğer sonuçlar ise Türkçe öğretmenlerinin noktalama işaretlerine yönelik Türkçe çalışma kitaplarında yer alan etkinlikleri yeterli sayıda ve nitelikte bulmadıkları ve noktalama işaretlerinin kullanım düzeyini belirlemeye yönelik büyük oranda yazılı metin çözümlemesi, boşluk doldurma, çoktan seçmeli test gibi ölçme ve değerlendirme çalışmaları yaptıklarıdır.
\end{abstract}

Anahtar Kelimeler: Noktalama işaretleri, öğretim, Türkçe öğretmeni

\begin{abstract}
In this research, Turkish teachers' opinions were taken about the teaching process of punctuation marks. It is thought that these views may be important in terms of methods, techniques, strategies and measures to be developed for teaching punctuation and can contribute to the development of basic language skills indirectly. In this context, the research aims to determine what kind of views and approaches Turkish teachers have regarding the process of teaching punctuation marks. The study group of this research involves thirty eight Turkish teachers. In the research, a semi-structure interview form which has six open-ended questions was used. To analyze the data obtained from the research, descriptive analysis method was used. In the research, it has been found that Turkish teachers are aware of the importance and function of punctuation marks to a large extent and that they prefer to use direct instruction and question-answer methods in their teaching of punctuation marks in basic language skills. Other results show that Turkish teachers find the activities of Turkish workbooks insufficient in both quality and quantity about punctuation and they use assessment and evaluation tools substantially to determine the usage level of punctuation marks such as written text analysis, gap filling and multiple choice test.
\end{abstract}

Keywords: Punctuation marks, teaching, Turkish teacher

\section{Giriş}

İnsanlar duygu ve düşüncelerini dil becerilerini kullanarak belirli bir cümle yapısı içinde aktarırlar. Bunu yaparken belirli kurallara uymak, doğru cümle veya metinlerle ifadeyi ortaya koymak gerekir. Bu bağlamda düzenleyici kurallar ve noktalama işaretleri önem oluşturur. (Maden, 2013). Noktalama işaretlerine ilişkin birçok görüşten söz edilebileceğini vurgulayan Truss'a (2003) göre bazı dilbilgisi uzmanları, noktalama işaretlerini dildeki dokuyu biçimlendiren bir dikiş aletine benzetir. Bazıları ise noktalama işaretlerini trafik işaretlerine benzeterek onların dile ilişkin yavaşla, fark et, yoldan çıkma ve dur gibi anlamlara geldiğini

\footnotetext{
*Bu çalışma, IX. Uluslararası Dünya Dili Türkçe Sempozyumu'nda sunulan bildirinin tam metnidir.

*** Doç. Dr., Abant İzzet Baysal Üniversitesi, Türkçe Eğitimi Anabilim Dalı, mkurudayi@hotmail.com

****̈̈̆retmen, MEB, onur.dolek@hotmail.com
} 
belirtir. Bu benzetmeye koşut olarak Aktaş ve Gündüz (2008, s. 407); Beyreli, Çetindağ ve Celepoğlu (2015, s. 26), noktalama işaretlerinin duygu ve düşünceleri daha açık ifade etmek, cümlenin yapısını ve duraklama noktalarını belirlemek, sözün vurgu ve ton gibi özelliklerini belirtmek, metnin okuyucu tarafından kolay ve çabuk anlaşılmasını sağlamak üzere kullanıldığına vurgu yapar.

Yazma becerisi öğretiminin önemli bir boyutunu, noktalama kurallarını etkili bir biçimde öğretme ve bu kuralları doğru bir biçimde uygulayabilme becerisi kazandırabilme oluşturur (Bağcı ve Karagül, 2013, s. 314). Bu öğretim kapsamında noktalama işaretlerinin düzgün kullanımı dilin işleyişini sağlama, dilin yapı ve anlam özelliklerini koruma, yazı dili ile konuşma dili arasında ilişsi kurma gibi açılardan önemlidir (Maden, 2013). TDK yazım k1lavuzu (2012, s. 27-38) bu önem ve amaç kapsamında 17 temel noktalama işaretine yer vermiştir. Bunun yanı sıra temel noktalama işaretlerinin dışında, "diğer işaretler" başlığı altında verilen işaretlerin sayısı ise 30 'dur. Böylelikle yazıda kullanılan toplam 47 işaretten söz edilebilir.

Konuşma, kelime grupları arasında kısa veya uzun süreli beklenmesi gereken bir eylemdir. Konuşma sırasında bazı kelimeler fark edilmeleri için daha güçlü, daha vurgulu söylenir. Ayrıca yüz ve eller de etkin bir biçimde kullanılabilir. Bunlarla anlam daha açık hale getirilebilir. Bütün bu yollar konuşmayı biçimlendirir. Yazmada durum farklıdır, ayrıca sözcüklerin biçimlendirilmesi gerekir. Öncelikle sözcükler arasında boşluk bırakılır. İkinci olarak yazmada noktalama işaretleri kullanılır. Noktalama yazının daha kolay bir biçimde yazılmasına ve açık bir biçimde anlaşılmasına yardımcı olur (Gordon, 1988, s. 5). Bir başka deyişle konuşmada sesin belirlediği anlatım değerini yazılı anlatımda noktalama işaretleri sağlar. Bu işaretler okumayı düzenleyerek yanlış anlaşılmayı önler (Kavcar, Oğuzkan ve Aksoy, 2012, s. 42). Aynı zamanda noktalama işaretleri okuyucuya yazıyı, yazarın söylediği gibi okutmak kolaylığı sağlar. Anlamın temel birimi olan cümleleri ayırarak anlamı etkili kılan noktalama işaretleri, okuyucunun ilgisini uyanık tutmasını da kolaylaştırır (Erten, 1959, s. 2; Kavcar, Oğuzkan ve Sever: 2004, s. 84). Bunun yanı sira Dawkins (1995) noktalama işaretlerinin, yazılı veya sözlü bütün düzyazı metinlerin oluşumunu sağlayan bağımsız cümleler arasındaki uygun ilişkileri göstermeye yaradığını belirtmiştir.

Noktalama işaretleri Türkçe öğretimi kapsamında değerlendirildiğinde, ilk bakışta yazma becerisinin geliştirilmesiyle ilgili bir husus olarak algılanabilir. Oysa okuma ve yazmanın simetrik beceriler olması sebebiyle bu işaretler, okuma becerisini de ilgilendirmektedir. Özellikle şiir gibi duygu ve düşünce yoğunluğu fazla olan edebî türlerde, noktalama işaretlerinin okuma/anlama süreci açısından ne derece önemli olduğu daha iyi anlaşılmaktadır (Onan, 2006). $\mathrm{Bu}$ nedenle noktalama işaretlerinin yazılı anlatımdaki işlevinin yanı sıra okumada da ne derece etkili olduğu öğrencilere anlatılmalı ve buna ilişkin etkinlikler düzenlemelidir. Nitekim 2015 Türkçe öğretim programında noktalama işaretlerinin akıcı okuma becerisi edinme konusundaki önemine yönelik kazanımlar yer alır.

Noktalama işaretlerin öğretimi en az harflerin öğretimi kadar zordur. Alfabeyle okuma yazmayı öğrendikten sonra yazıda gördüğü harf dışındaki işaretleri tanımayan bir öğrencinin okuma ve yazmasın yeterli olabileceğini söylemek olanaklı değildir. Noktalama işaretleri yazılı anlatım çalışmalarıyla öğretilmeli bunun için ayrı bir ders yapılmamalıdır. Ayrıca noktalama öğretiminde imla kılavuzundan yararlanılmalı ve işaretlerin okuma değeri belirtilmelidir. Noktalama ögrretimi belli başlı metinlere dayandırılmalı ve çeşitli üslup örnekleriyle yapılmalı, noktalama öğretimine birinci sınıftan başlanmalı ve noktalama işaretlerinin hepsi bir arada öğretilmemelidir (Adıgüzel 2004, s. 214-219). Bu konuda yeni öğretim programları yapılandırmacı yaklaşımı temel almaktadır. Yapılandırmacı anlayışta merkez öğrencidir ve bir konu öğrenciyi etkin hale getirecek etkinlikler yoluyla sezdirilir. Öğretmen öğrenciye küçük yönlendirmelerde bulunabilir ancak hedefe öğrencinin kendisinin ulaşması gerekir (Kerimoğlu, 2016, s. 198). Bu anlayış doğrultusunda noktalama işaretlerinin bir önceki sınıflardaki işlevlerinin hatırlatılması ve öğrencinin var olan bilgilerinin harekete geçirilmesi gerekir.

Öğrencinin yazma öz yeterliliklerine ilişkin bir değerlendirme yapmak istendiğinde uygun bir noktalamaya sahip basit bir cümleden daha kapsamlı yargılar içeren paragraf 
oluşturmaya kadar değişen bir sürecin denetlenmesi gerekir (Pajares ve Valiante, 2006, s. 161). Buradan hareketle yazma ediniminin gerçekleşmesinde, yazma becerilerinin geliştirilmesinde ve değerlendirilmesinde noktalamanın kazandırılması gereken ilk beceriler arasında olduğu söylenebilir. Nitekim zihinsel işlevlerle birlikte noktalama yazının temelini oluştur. Noktalamanın ihmal edilip eksik bırakılması yazının anlaşılır olması ve kolay kavranması bakımından çeşitli güçlükler doğurur. Okuyucunun metinde anlam bağını kuramamasına neden olur. Noktalamanın yer almadığı bir metinde özellikle de devrik cümlelerde bir yargının nerede bitip, diğerinin nerede başladığı karıştırılabilir. Öte yandan noktalama işaretlerinin aşırı bir şekilde kullanıldığı yazıda da düşünce birliğinin ve anlatım rahatlığının saplanamadığı görülür (Kalfa, 2012, s. 209-211). Kısaca bir yazıda noktalama işaretlerinin eksik ya da aşırı kullanılması metnin biçimsel ve anlamsal özelliklerini olumsuz etkiler.

Yazılanların söylenenlere göre daha kalıcı olduğu düşünüldüğünde noktalama işaretlerin amaca uygun kullanılması gerekir. Bu doğrultuda 2006 ve 2015 Türkçe öğretim programlarında öğrencilere öğretilmek üzere 13 noktalama işaretine değinilir. Her iki programda da noktalama işaretlerine ilişkin kazanımlar, öğrencilerin gelişim düzeylerine uygun olarak aşamalı bir biçimde verilmiştir ve öğretim sürecinde öğrencilerin edinecekleri bilgi, beceri ve alışkanlıkları kapsamaktadır (MEB, 2006; MEB, 2015). Ayrıca 2015 programında akıcı okuma altında noktalama işaretlerine dikkat edilmesi gerektiği üzerinde durulur.

Alanyazın incelendiğinde genellikle noktalama işaretlerinin kullanım becerilerine ve bazı yöntem, teknik ve stratejilerin noktalama işaretlerinin öğretimindeki işlevine yönelik çalışmalar (Uludağ, 2002; Ergin, 2009; Kara, 2010; Karakoyun, 2010; Kırbaş, 2010; Maden, 2013; Sever ve Memiş, 2013) olduğu görülmektedir. Buna karşılık yapılandırmacı yaklaşımla birlikte rehber konumunda bulunan öğretmenlerinin noktalama işaretlerinin öğretilmesi sürecine ilişkin görüşlerini ortaya koyan bir çalışma bulunmamaktadır. Yukarıda noktalama işaretlerinin önemine ve işlevine ilişkin ortaya konan yaklaşımlara koşut olarak noktalama işaretlerinin öğretimi süreci ile ilgili Türkçe öğretmenlerinin görüşlerine başvurulmuştur. Bu görüşlerin noktalama öğretimine yönelik geliştirilebilecek yöntem, teknik, stratejiler ve alınacak önlemler konusunda önemli olabileceği düşünülmektedir. Öte yandan öğretmenlerin görüşlerinden hareketle elde edilecek verilerin noktalama işaretleri kullanım becerilerinin ve dolayısıyla temel becerilerin geliştirilmesine katkı sağlayabileceği söylenebilir. Bu bağlamda araştırmanın amacı noktalama işaretlerinin öğretilmesi sürecine ilişkin Türkçe öğretmenlerinin ne tür görüş ve yaklaşımlara sahip olduğunu belirlemektir. Bu amaç doğrultusunda aşağıdaki sorulara yanıt aranmıştır:

1. Öğretmenlerin noktalama işaretlerinin önemi ve işlevi hakkındaki görüşleri nelerdir?

2. Öğretmenlerin noktalama işaretlerinin öğretiminde kullandıkları teknik, yöntem ve stratejiler nelerdir?

3. Öğrencilerin öğrenmekte ve uygulamakta en çok zorlandığı noktalama işaretleri hangileridir?

4. Öğrencilerin en kolay kavradığı noktalama işaretleri hangileridir?

5. Noktalama işaretlerinin kullanım düzeylerini belirlemeye ilişkin ne tür ölçme ve değerlendirme çalışmaları yapılmaktadır?

6. Noktalama işaretlerinin öğretimine ilişkin Türkçe çalışma kitaplarında yer alan etkinlikler hakkındaki öğretmen görüşleri nelerdir?

\section{Yöntem}

\section{Araştırmanın deseni}

$\mathrm{Bu}$ araştırma, noktalama işaretlerinin öğretiminde öğretmen görüşlerini ve yaklaşımlarını saptamaya ilişkin nitel bir çalışmadır. Nitel araştırma, gözlem, görüşme ve doküman analizi gibi nitel veri toplama yöntemlerinin kullanıldığı, algıların ve olayların doğal ortamda gerçekçi ve bütüncül bir biçimde ortaya konmasına yönelik nitel bir sürecin izlendiği araştırmadır (Yıldırım 
ve Şimşek, 2016, s. 41). Nitel araştırmada araştırmacılar; verileri inceler, onlardan bir anlam çıkarır ve veri kaynaklarını kapsayan kategorileri veya temaları belirler (Creswell, 2016, s. 186).

\section{Çalışma grubu}

Araştırmaya 2016-2017 eğitim-öğretim yılının ikinci döneminde Gaziantep ilinde görev yapan 38 Türkçe öğretmeni katılmıştır. Araştırmaya katılan öğretmenlerin hizmet sürelerine ilişkin bilgiler Tablo 1'de belirtilmiştir.

Tablo 1

Öğretmenlerin Hizmet Sürelerine İlişkin Dağılımlar

\begin{tabular}{lcl}
\hline Mesleki Y1l Aralığ & N & \% \\
\hline $1-3$ & 11 & 28.94 \\
$4-7$ & 17 & 44.73 \\
$8-11$ & 3 & 7.89 \\
11 yll ve üstü & 7 & 18.42 \\
\hline Toplam & 38 & 100 \\
\hline
\end{tabular}

Bu tabloya göre araştırmaya 1-3 yaş aralığında $11 ; 4-7$ yaş aralığında $17 ; 8-11$ yaş aralığında 3; 11 ve üstü yaşlarda ise 7 öğretmen katılmıştır.

\section{Verilerin toplanması ve çözümlenmesi}

Noktalama işaretlerinin öğretimi sürecine ilişkin öğretmen görüş ve yaklaşımlarını belirlemeyi amaçlayan bu çalışmanın verileri yarı yapılandırılmış görüşme formu aracılığıyla toplanmıştır. $\mathrm{Bu}$ bağlamda hazırlanmış yarı yapılandırılmış görüme formunda 6 açık uçlu soru bulunmaktadir.

Araştırmanın yarı yapılandırılmış görüşme formunda yer alan sorulara ilişkin 2 Türkçe eğitimi uzmanından görüş alınmış, bu görüşler doğrultusunda sorular üzerinde bazı düzenlemeler yapılmıştır. Daha sonra uygulama dışında kalan 5 öğretmene bu form uygulanmış, gelen yanıtlar alan uzmanlarıyla birlikte incelenmiş ve formda yer alan 2 soru çıkarılmıştır. Ayrıca soruların açık ve anlaşılır olup olmadığı yine alan uzmanlarıyla tartışılmış ve forma son biçimi verilmiştir. Böylelikle soruların iç geçerliliği sağlanmaya çalışılmıştır. İç geçerlilik; veri toplama süreci, verilerin çözümlenmesi ve yorumlanması süreçlerinde araştırmacının tutarlı olması ve bu tutarlılığı nasıl sağladığını açıklaması ile ilgilidir. Araştırmacının sürekli olarak kendisini ve araştırma süreçlerini eleştirel bir gözle sorgulaması ve bulguların gerçeği yansıtıp yansıtmadığını denetlemesi önemlidir. Geçerliliğin sağlanmasında elde edilen veriler ve sonuçlar üzerinde meslektaş ve katılımcı teyidi gibi bazı ek yöntemler kullanılması gerekir (Yıldırım ve Şimşek, 2016, s. 270-271). İç geçerlilikte amaç, bilimsel nedensellik kanıtını sağlamaktır (Johnson ve Christensen, 2014, s. 270). Bu bilgiler doğrultusunda araştırma sorularının geçerlilik açısından belirtilen ölçütleri sağladığı düşünülmüş ve sorular çalışma grubuna uygulanmıştır.

Çalışmadan elde edilen verilerin çözümlenmesinde betimsel çözümleme yöntemi kullanılmıştır. Betimsel çözümlemede veriler araştırma sorularının ortaya çıkardığı temalara göre düzenlenebileceği gibi, görüşme sürecinde kullanılan sorular ya da boyutlar dikkate alınarak da sunulabilir. Betimsel çözümlemede katılımcıların görüşlerini çarpıcı bir biçimde yansıtmak amacıyla doğrudan alıntılara sık sık yer verilir (Yıldırım ve Şimşek, 2016, s. 239). $\mathrm{Bu}$ çözümleme yaklaşımının amacı belirli bir veri kümesini tanımlamak, özetlemek ya da anlamlandırmaktır (Johnson ve Christensen, 2014, s. 451). Araştırmada, görüşme sorularına yönelik verilen yanıtlar doğrultusunda temalar ve alt temalar oluşturulmuş ve bu temalar kapsamındaki görüşlerin katılımcı sayısı belirtilmiştir. Temalar kapsamında katılımcı sayısı yüksek olan görüşlere ilişkin katılımcılardan doğrudan alıntılar yapılmıştır. Çalışmada, doğrudan alıntılarda katılımcıların ismi yerine katılımcı 1 (K.1), katılımcı 14 (K.14) biçiminde kısaltma ve kodlama yapılmıştır. 


\section{Bulgular}

Araştırmanın bu bölümünde yarı yapılandırılmış görüşme formunda yer alan sorulara verilen yanıtlardan elde edilen bulgular ortaya konmuştur. Bulgular 6 ana tema çerçevesinde sunulmuştur. Bu temalardan ilki Türkçe öğretmenlerinin noktalama işaretlerinin önemi ve işlevi hakkındaki görüşlerini içermektedir. Bu doğrultuda öğretmenlerden gelen yanıtların dağılımı Tablo 2'de verilmiştir.

Tablo 2

Öğretmenlerin Noktalama İşaretlerinin Önemi ve İşlevi Hakkındaki Görüşleri

\begin{tabular}{lcc}
\hline Görüsşler & $\mathrm{f}$ & $\%$ \\
\hline Metnin daha iyi anlaşılmasını sağlar. & 25 & 65.78 \\
Yazıdaki anlam karışılı̆ıını önler. & 15 & 39.47 \\
Yazıda jest-mimik, vurgu, tonlama ve duraksama işlevi & 14 & 36.84 \\
görür. & 2 & 5.26 \\
Cümlelerin başlangıç ve bitiş yerlerini gösterir. & 2 & 5.26 \\
Okumayı kolaylaştırır. & 1 & 2.63 \\
Kavranmaması halinde kaygı oluşturur. & 1 & 2.63 \\
Yazının amaca ulaşmasını sağlar. & 1 & 2.63 \\
Estetik açıdan yazıya katkı sağlar. & 1 & 2.63 \\
Yazma eğitimi üzerinde çok fazla etkisi yoktur. & & \\
\hline
\end{tabular}

Tablo 2'de, Türkçe öğretmenlerinin noktalama işaretlerinin önemi ve işlevi hakkında en çok "metnin daha iyi anlaşılmasını sağlar", "anlam karışıklığını önler" ve "yazıda jest-mimik, vurgu, tonlama, duraksama işlevi görür" biçiminde görüş bildirdikleri görülmektedir. Noktalama işaretlerinin önemi ve işlevine ilişkin bazı öğretmen görüşleri aşağıda verilmiştir.

"Noktalama işaretleri yazının daha iyi anlaşılmasını sağlar. Karmaşıklığı önler, yazıyı düzene sokarak daha kullanışlı hale getirir. Noktalama işaretleri düzgün kullanılmadığında cümlelerin nerede başlayıp nerede bittiği anlaşılmaz (K6).”

"Noktalama işaretleri yazı için düzen sağlayıcıdır. Yazıdaki duygu, düşünce ve ifadelerin istenen bir şekilde iletilebilmesi açısından önemlidir. Nasıl ki toplumu düzenleyen örf, adet, gelenek, görenek gibi kurallar varsa yazı da noktalama işaretleri vardır. Kimi zaman duyguları ifade eder kimi zaman anlam karmaşasını önler. Kısaca yazının mimikleridir (K9).”

"Noktalama işaretleri cümlenin daha açık ve anlaşılır olmasını sağlar. Okumayı ve anlamayı kolaylaştırmak amacıyla noktalama işaretlerini kullanmak önemlidir. Ayrıca vurgu ve tonlamalar için de önemlidir (K18).”

Belirlenen temalardan ikincisi noktalama işaretlerinin öğretiminde kullanılan yöntem, teknik ve stratejileri içermektedir. Bu doğrultuda öğretmenlerden gelen yanıtların dağılımı Tablo 3'te verilmiștir:

Tablo 3'te, noktalama işaretlerinin öğretimine ilişkin yapılan çalışmalarda öğretmenlerin "düz anlatım", "soru-cevap", "buluş yolu ile öğretim", "görsel sunu" ve "drama" gibi yöntem, teknik ve stratejileri daha çok yeğledikleri görülmektedir. Tablo 3'ün alt temalarından biri olan "Diğer" bölümünde gösteri, tartışma, proje temelli yaklaşım, rol oynama, kavram haritaları ve gösterip yaptırma gibi yanıtlar yalnızca birer Türkçe öğretmeni tarafindan yeğlenmiştir. Öğretmenlerin bu temaya ilişkin bazı görüşleri aşağıda verilmiştir:

"Noktalama işaretlerinin öğretiminde grup çalışmalarının önemli olduğunu düşünüyorum. Özellikle noktalama işaretlerini etkinliklerle kavratmaya çalışmak son 
derece yararlıdır. Düz anlatım yöntemi belli bir noktaya kadar etkisini gösteriyor fakat bunu diğer yöntemlerle birleştirince etkisi ortaya çıkıor... (K16).”

"Öğretim sürecinde öncelikle anlatım tekniğini kullanıyorum. Tabi ki anlatım tekniği tek başına yeterli değildir. Bunun yanında çeşitli görseller, videolar ve öğrencilerin de aktif olarak katıldığı bazı oyunlar kullanıyorum. Noktalama işaretlerinin eksik olduğu bir metni doldurmak da yöntemlerim arasındadır (K21).”

"Anlatım tekniğini daha çok kullanıyorum. Soru-cevap, beyin firtınası, darama ve proje gibi yöntemlere de zaman zaman yer veriyorum (K26)."

"Genellikle buluş yoluyla öğrenme stratejisini kullanıyorum. Yöntem olarak da bilmecelerle öğretme yöntemini kullanıyorum (K29)."

Tablo 3

Öğretmenlerin Noktalama İşaretlerinin Öğretiminde Kullandıkları Teknik, Yöntem ve Stratejiler

\begin{tabular}{lcc}
\hline Kullanılan yöntem, teknik ve stratejiler & $\mathrm{f}$ & $\%$ \\
\hline Düz anlatım & 23 & 60.52 \\
Soru cevap & 11 & 28.94 \\
Buluş yoluyla öğretim & 10 & 26.31 \\
Görsel sunu & 7 & 18.42 \\
Drama & 6 & 15.78 \\
Beyin firtınası & 4 & 10.52 \\
Grupla çalışma & 4 & 10.52 \\
Animasyon/video & 2 & 5.26 \\
Sesli okuma & 2 & 5.26 \\
Tümevarım/tümden gelim & 2 & 5.26 \\
Eğitsel oyunlar & 2 & 5.26 \\
Diğer & 8 & 21.05 \\
\hline
\end{tabular}

Belirlenen temalardan üçüncüsü öğrencilerin öğrenmekte ve uygulamakta en çok zorlandığı noktalama işaretlerini içermektedir. Bu doğrultuda öğretmenlerden gelen yanıtların dağılımı Tablo 4'te verilmiştir:

Tablo 4

Öğrencilerin Öğrenmekte ve Uygulamakta En Çok Zorlandığı Noktalama İşaretleri

\begin{tabular}{lcc}
\hline Zor kavranan noktalama İşaretleri & $\mathrm{f}$ & $\%$ \\
\hline Noktalı virgül & 34 & 89.47 \\
İki nokta & 14 & 36.84 \\
Virgül & 10 & 26.31 \\
Eğik çizgi & 2 & 5.26 \\
Kısa çizgi & 2 & 5.26 \\
Köşeli yay ayraç & 2 & 5.26 \\
Ünlem & 2 & 5.26 \\
Diğer & 4 & 10.52 \\
\hline
\end{tabular}

Tablo 4'e bakıldığında, öğrencilerin öğrenmekte ve uygulamakta en çok zorlandığ noktalama işaretlerinin "noktalı virgül", "iki nokta" ve "virgüll" olduğu görülmektedir. Araştırmaya katılan öğretmenlerin büyük bir çoğunluğu, bu duruma neden olarak öğrencilerin zor kavranan işaretlerin işlevlerini karıştırmasını göstermektedir. Bunun yanında bazı öğretmenler ise bu durumun nedenini "öğretim metodu yetersizliği, ilkokul eğitiminin yetersizliği, işaretlerin kullanım alanının genişliği” biçiminde açıklamıştır. Tablo 4'ün alt 
temalarından biri olan "Diğer" bölümünde tırnak işareti, kesme işareti, konuşma çizgisi ve üç nokta gibi işaretler yer almaktadır. Bu işaretler, katılımcılar tarafından birer kez yanıtlandığı için diğer bölümünde yer almıştır. Öğrencilerin öğrenmekte ve uygulamakta en çok zorlandığ 1 noktalama işaretlerine ilişkin bazı görüşler aşağıda verilmiştir:

"Ünlemi uygularken çok zorlanıyorlar. Çünkü yazılı anlatımda cümlenin verdiği duyguyu ya da seslenmeyi anlayamıorlar (K1)."

"Virgül ve noktalı virgül konuları öğrenciler arasında daha güç anlaşılan noktalama işaretledir. Ayrıca bu iki işaret bazı yerlerde karıştırılmaktadır. Özellikle virgülün benzer özelliklere sahip yerlerde kullanımı bu işaretin anlaşılmasını zorlaştırdığını düşünüyorum (K3).”

"Noktalama işareti ile iki nokta. Diğer noktalama işaretlerine göre daha karmaşık bir yapıya sahip olmasından kaynaklanıyor olabilir. Tabi kullandığımız metodun yetmezliği de önemli derecede etkiliyor olabilir (K32).”

Belirlenen temalardan dördüncüsü öğrencilerin en kolay kavradığı noktalama işaretlerini içermektedir. Bu doğrultuda öğretmenlerden gelen yanıtların dağılımı Tablo 5 'te verilmiştir:

Tablo 5

Öğrencilerin Kolay Kavradığı Noktalama İşaretleri

\begin{tabular}{lcc}
\hline Kolay kavranan işaretler & f & \% \\
\hline Nokta & 35 & 92.10 \\
Soru işareti & 22 & 57.89 \\
Virgül & 9 & 23.68 \\
Ünlem & 8 & 21.05 \\
Üç nokta & 3 & 7.89 \\
Diğer & 3 & 7.89 \\
\hline
\end{tabular}

Tablo 5'e göre öğrencilerin en kolay kavradığı noktalama işaretlerinin "nokta" ve "soru işareti" olduğu görülmektedir. Araştırmaya katılan öğretmenlerin çoğu, bu işaretlerin ilk öğrenilen işaretler olmasının ve sık kullanılmasının öğrenilmeye olumlu yönde etki ettiğini belirtmiştir. Tablo 5'in alt temalarından biri olan "Diğer" bölümünde tırnak işareti, kesme işareti ve konuşma çizgisi yer almaktadır. Öğrencilerin kolay kavradığı noktalama işaretlerine ilişkin bazı görüşler aşağıda verilmiştir:

"En kolay öğrendikleri noktalama işareti noktadır. İlk öğrendikleri noktalama işareti olduğundan ve metinlerde daha çok karşılaştıklarından bu işaret onlarda kalıcı oluyor (K10).”

“Öğrencilerin en kolay kavradığı noktalama işaretleri: Nokta, virgül, ünlem, soru işareti ve konuşma çizgisidir. Bunun nedeni kullanma sıklığ kavranmasidır (K13).”

"Noktayı öğrenme konusunda hızlı algıladıklarını düşünüyorum. Kullanıldığı yerlerin net ve diğer işaretlerden farklı oluşunun ayırt edici olduğunu gözlemledim. Farklılık, şekilselden ziyade anlamsal olarak ortaya çıkmaktadır. Daha az karmaşık gelmektedir (K22)." 
"Soru işareti. Çünkü bir bebek bile soru sorarak dili ve hayatı öğreniyor. Dolayısı ile soru işareti ve kullanımı hayatın içinde (K33)."

Belirlenen temalardan beşincisi noktalama işaretlerinin kullanım düzeylerini belirlemeye ilişkin yapılan ölçme ve değerlendirme çalışmalarını içermektedir. Bu doğrultuda öğretmenlerden gelen yanıtların dağılımı Tablo 6'da verilmiştir:

Tablo 6

Noktalama İşaretlerinin Kullanım Düzeylerini Belirlemeye İlişkin Yapılan Ölçme ve Değerlendirme Çalışmaları

\begin{tabular}{lcc}
\hline Ölçme ve değerlendirme çalışmaları & f & \% \\
\hline Yazılı metin çözümlemesi & 22 & 57.89 \\
Boşluk doldurma & 20 & 52.63 \\
Çoktan seçmeli test & 15 & 39.47 \\
\hline Soru-cevap & 3 & 7.89 \\
Diğer & 4 & 10.52 \\
\hline
\end{tabular}

Tablo 6'da Türkçe öğretmenlerinin noktalama işaretlerinin kullanım düzeylerini belirlemeye ilişkin "yazılı metin inceleme", "boşluk doldurma" ve "çoktan seçmeli test" i daha çok yeğledikleri görülmektedir. Tablo 6'nın alt temalarından biri olan "Diğer" bölümünde sözlü sınav, doğru-yanlış, metin okutma ve yazılı anlatım değerlendirme ölçeği yanıtları yer almaktadır. Noktalama işaretlerinin kullanım düzeylerini belirlemeye ilişkin yapılan ölçme ve değerlendirme çalışmalarına ilişkin bazı görüşler aşağıda verilmiştir:

"Defterlerini kontrol etmeye çalışıyorum. Yazı yazdıklarında kompozisyon yazdıklarında noktalama işaretlerine dikkat edip etmediklerine bakıyorum. Ayrıca değerlendirme yapmıyorum. Yazılı sınavlarda da mutlaka noktalama ile ilgili bir soru soruyorum (K5)."

"Boşluk doldurma ile ne kadar öğrenebildikleri hakkında ölçme yapabiliyorum. Sonuçlara göre öğrencilere dönüt verebiliyorum (K25).”

"Metin üzerinde çalışma, düzeltme, boşluk doldurma, metin yazdırma, şiir ve düzyazı gibi metinler okutma, yazılı anlatım değerlendirme ölçeği (K36).”

Araştırmada belirlenen son tema, noktalama işaretlerinin öğretimine ilişkin Türkçe çalışma kitaplarında yer alan etkinlikler hakkındaki öğretmen görüşlerini içermektedir. Bu doğrultuda öğretmenlerden gelen yanıtların dağılımı Tablo 7'de verilmiştir:

Tablo 7

Noktalama İşaretlerinin Öğretimine İlişkin Türkçe Çalışma Kitaplarında Yer Alan Etkinlikler Hakkındaki Öğretmen Görüşleri

\begin{tabular}{lcc}
\hline Görüşler & f & $\%$ \\
\hline Yeterli sayıda ve nitelikte değil & 23 & 60.52 \\
Yeterli sayıda ve nitelikte & 9 & 23.68 \\
Yeterli sayıda ancak nitelikte değil: & 4 & 10.52 \\
Nitelikli ancak yeterli sayıda değil & 2 & 5.26 \\
\hline
\end{tabular}

Tablo 7'de araştırmaya katılan Türkçe öğretmenlerinin \%60.52'si noktalama işaretlerinin öğretiminde Türkçe çalışma kitaplarında yer alan etkinliklerin yeterli sayıda ve nitelikte olmadığı; \%23.68'i ise yeterli sayıda ve nitelikte olduğu yönünde görüş bildirmişlerdir. Olumsuz görüş bildirenlerin çoğu, boşluk doldurma ve çoktan seçmeli teste yönelik etkinlik 
sayılarının artırılması, etkinliklerin görsellerle desteklenmesi ve farklı noktalama işaretlerine de yer veren etkinlikler olması gerektiğini belirtmişlerdir. Öğretmenlerin Türkçe çalışma kitaplarında noktalama işaretlerinin öğretimine yönelik etkinlikler hakkındaki bazı görüşleri aşağıda verilmiştir:

"Genel anlamda çalışma kitaplarındaki etkinlikleri yeterli buluyorum. Belki noktalama işaretlerine yönelik yazma çalışması etkinlikleri daha fazla olabilirdi (K3)."

"Etkinlikleri yeterli bulmuyorum. Görsel açıdan zengin ve birden fazla duyu organına hitap eden etkinlikler yapılmasını öneriyorum (K6)."

"Kitaplarda noktalama işaretleri için az sayıda ve verimsiz etkinlik hazırlanmıştır. Öğrencilerin tam olarak kavrayamadığını düşünüyorum (K22)."

"Yeterli değil; çünkü çocukların ilerlemesinde önemli bir yer tutan sınavlara hazırlamada yetersiz kalıyor. Bu nedenle metin çalışmaları ihmal edilmeden çoktan seçmeli testlere ağırlık verilebilir (K23).”

"Ders kitaplarında noktalama işaretleri ile ilgili etkinlik sayısının yeterli olduğunu düşünüyorum. Yalnız genellikle bu etkinlikler hep aynı tarzda olduğu için (yay ayraçla belirtilen alanlara uygun noktalama işaretlenin getiriniz gibi) zaman zaman öğrencilerin sıkılmasına neden olmaktadır. Bu işaretlerle ilgili etkinliklerin öğrenciyi daha etkin kılacak ve araştırmaya sevk edecek şekilde hazırlanması gerektiğini düşünüyorum (K35)."

\section{Sonuç, Tartışma ve Öneriler}

$\mathrm{Bu}$ araştırmada Türkçe öğretmenlerinin noktalama işaretlerinin öğretimine ve değerlendirilmesine ilişkin ne tür görüş ve yaklaşımlara sahip olduğunu belirlemek amaçlanmıştır. Araştırmadan, Türkçe öğretmenlerinin noktalama işaretlerinin temel becerilerdeki önem ve işlevinin büyük oranda farkında olduğu sonucu elde edilmiştir. Bu farkındalık sonucunda Türkçe öğretmenlerinden noktalama işaretlerinin öğretiminde etkin rol oynamaları, buna yönelik etkinlikler geliştirmeleri ve doğru ölçme değerlendirme yapmaları beklenir. $\mathrm{Bu}$ doğrultuda araştırmada öğretmenlerin noktalama işaretlerinin öğretiminde kullandıkları teknik, yöntem ve stratejiler sorgulanmıştır. Buradan elde edilen sonuç araştırmaya katılan Türkçe öğretmenlerinin \%60.52'sinin düz anlatım tekniğini; \%28.94'ünün soru-cevap yöntemini ve \%26.31'inin buluş yoluyla öğretim stratejisinden yararlandığı; buna karşın drama, beyin fırtınası ve grupla öğrenme gibi yapılandırmacı yaklaşımın öngördüğü öğrenciyi sürece dâhil eden yöntem ve teknikleri düşük oranlarda kullandığıdır. Oysa alanyazında yapılandırmacı yaklaşımın öngördüğü yöntem ve tekniklerin sınandığı çalışmalarda noktalama işaretlerini kullanım düzeylerinin geliştiği saptanmıştır. Dölek ve Hamzadayı (2016) tarafından yapılan çalışmada akran etkileşimine yönelik geliştirilen yazma etkinliklerinin öğrencilerin noktalama ve yazım becerilerini geliştirdiği sonucuna ulaşılmıştır. Maden (2013) tarafından yapılan çalışmada ise aktif öğrenme tekniklerinin 6. sınıf öğrencilerin yazım ve noktalama kurallarına yönelik akademik başarıları ve derse karşı tutumları üzerinde geleneksel öğretim yöntemine göre daha etkili olduğu saptanmıştır. Benzer bir biçimde Sever ve Memiş (2013) de yapmış oldukları çalışmada öğrencinin merkeze alındığı süreç temelli yazma modellerinin öğrencilerin noktalama becerisini olumlu yönde etkilediği sonucuna ulaşmışlardır. Buradan hareketle noktalama işaretlerinin öğretiminde Türkçe öğretmenlerinin yapılandırmacı yaklaşımın öngördüğü, öğrencinin sürecin içinde etkin olduğu teknik ve yöntemlere daha fazla ağırlık vermesi gerektiği söylenebilir. Öte yandan alanyazında geleneksel öğretimin bir parçası olmasına karşın bilişsel yönü güçlü olan bazı tekniklerin noktalama kurallarını uygulama becerilerini geliştirdiğini gösteren çalışmalar da vardır. Nitekim Hamzadayı ve Çetinkaya 
(2013) tarafından yapılan çalışmada dikte uygulamalarının öğrencilerin yazım ve noktalama kurallarını uygulama becerilerini geliştirdiği sonucuna ulaşılmıştır.

Araştırmadan elde edilen bir diğer sonuç ise öğrencilerin kavramakta ve uygulamakta en çok zorlandıkları noktalama işaretlerinin noktalı virgül ve iki nokta; en kolay kavradıkları noktalama işaretlerinin ise nokta ve soru işareti olduğudur. Virgülün öğrenciler tarafindan ne ölçüde kavrandığı konusunda öğretmenler kararsız kalmıştır. Bağcı (2011) tarafından noktalama ve yazım kurallarını uygulayabilmeye yönelik yapılan çalışmada da öğrencilerin nokta ve noktalı virgülü doğru kullanabilme düzeyleri öğretmenlerin bu görüşlerini destekler niteliktedir. Karaboğa (2011) tarafindan yapılan yüksek lisans tezinde de benzer sonuçlar elde edilmiştir. Bu araştırmada Türkçe öğretmenliği birinci sınıf öğrencilerinin noktayı iyi düzeyde; noktalı virgülü ise zayıf düzeyde kullandığı sonucuna ulaşılmıştır. Buradan hareketle erken dönemlerdeki noktalama işareti sorunlarının ileriki dönemlerde de benzer bir biçimde devam ettiği sonucuna varılabilir.

Araştırmadan elde edilen sonuçlardan bir diğeri öğretmenlerin noktalama işaretlerinin kullanım düzeyini belirlemeye yönelik büyük oranda yazılı metin çözümlemesi, boşluk doldurma ve çoktan seçmeli test gibi ölçme ve değerlendirme çalışmaları yaptığıdır. Buna karşın öğretmenlerin görece düşük bilişsel beceri gerektiren doğru-yanlış gibi yöntemleri kullanmaktan kaçındığı görülür. Buna göre öğrencilerin noktalama işaretlerini kullanım becerilerini ölçmek ve değerlendirmek üzere öğretmenlerin farklı tekniklerden yararlandığı ve rastlantı sonucu doğru yapmaların önüne geçmek için iki seçenekli doğru-yanlış testlerini tercih etmedikleri söylenebilir. Yazılı metinler öğrencinin noktalama işaretlerini uygulama alanıdır. Öğrenciler, noktalama işaretlerini kullanım becerilerini tam anlamıyla yazılı metinlere yansıtır. $\mathrm{Bu}$ doğrultuda öğretmenlerin büyük bir bölümünün öğrencilerin noktalama işaretlerini kullanımına ilişkin becerilerini ölçmek için yazılı metin çözümlemelerine başvurmalarının doğru bir yaklaşım olduğu düşünülmektedir.

Öte yandan noktalama işaretlerinin okuma becerilerinin geliştirilmesindeki işlevi düşünüldüğünde noktalama işaretlerinin öğretimine yönelik kullanılan yöntem ve tekniklerin sadece \%5.26 oranında okuma ile ilgili olması ve ölçme değerlendirme işlemleri sırasında okumanın hiç hesaba katılmaması da dikkat çekicidir. Buna göre öğretmenlerin noktalama işaretleri kullanım becerilerini saptarken okuma becerisine yönelik ölçme ve değerlendirme çalışmalarına yer vermedikleri söylenebilir. Bu konuda Baydık, Ergül ve Kudret (2012) tarafından yapılan bir çalışmada okuma güçlügü olan öğrencilerde en sık görülen sorunun noktalama işaretlerine dikkat etmeden okuma olduğu belirlenmiştir. Ayrıca öğretmenlerin ölçme ve değerlendirme sonucunda öğrencilere dönüt vermeleri de gerekir. Pakaz (2007) yapmış olduğu çalışmada, ipucu ve geri bildirim tekniklerinin öğrencilerin noktalama hatalarını büyük oranda azalttığı sonucuna ulaşmıştır.

Araştırmadan elde edilen son bulgulara göre araştırmaya katılan Türkçe öğretmenlerinin $\% 60.52$ 'si, Türkçe çalışma kitaplarında yer alan noktalama işaretlerine yönelik etkinliklerin yeterli sayıda ve nitelikte olmadığı görüşündedir. Buna karşın araştırmaya katılan öğretmenlerin $\% 23.68$ 'i, etkinliklerin yeterli sayıda ve nitelikte olduğu yönünde görüş bildirmiştir. Buna göre Türkçe çalışma kitaplarında yer alan noktalama işaretlerinin öğretimine yönelik etkinliklerin sayısının ve -bazı yönlerden desteklenerek- niteliğinin artırılması gerektiği düşünülmektedir.

\section{Kaynaklar}

Adıgüzel, M. S. (2004). Türkçe öğretim yöntemleri. İstanbul: Yeryüzü Yayınevi.

Aktaş, Ş. ve Gündüz, O. (2008). Yazılı ve sözlü anlatım (9. Baskı). Ankara: Akçağ Yayınları.

Bağcı, H. (2011). İlköğretim 8. sınıf öğrencilerinin noktalama işaretleri ile yazım kurallarını uygulayabilme düzeyi. Türkish Studies, 6(1), 693-706.

Bağc1, H. ve Karagül S. (2013). Yazım ve noktalama eğitimi. A. Güzel ve H. Karatay (Yay. haz.). Türkçe Öğretimi El Kitabı içinde (s. 307-334). Ankara: Pegem Akademi. 
Baydık, B., Ergül, C. ve Bahap Kudret, Z. (2012). Okuma güçlüğü olan öğrencilerin okuma akıc1lığ sorunları ve öğretmenlerinin bu sorunlara yönelik öğretim uygulamaları. Illkögretim Online, 11(3), 778-789.

Beyreli, L., Çetindağ, Z. ve Celepoğlu, A. (2015). Yazılı ve sözlü anlatım (8. Bask1). Ankara: Pegem Akademi.

Creswell, J. W. (2016). Araştırma deseni: Nitel, nicel ve karma yöntem ve yaklaşımları (2. Bask1). S. B. Demir (Çev. Ed.), Ankara: Eğiten Kitap.

Dawkins, J. (1995). Teaching punctuation as a rhetorical tool. CCC, 46(4), 533-548.

Dölek, O. ve Hamzadayı, E. (2016). Akran etkileşimine dayalı yazma etkinliklerinin 7. sınıf öğrencilerinin yazılı anlatım becerileri üzerindeki etkisi. Turkish Studies, 11(3), 965980.

Ergin, S. (2009). İlköğretim 8. sinıf ögrencilerinin noktalama işaretlerini kullanma becerileri (Yayımlanmamış yüksek lisans tezi). Gazi Üniversitesi Eğitim Bilimleri Enstitüsü, Ankara.

Erten, C. (1959). Örneklerle noktalama (3. Baskı). İstanbul: Bilgin Çocuk Yayınları.

Gordon, I. (1988). Punctuation. Hong Kong: Longman English Guides.

Hamzadayı E. ve Çetinkaya G. (2013). Dikte uygulamalarının 5. sınıf öğrencilerinin yazım ve noktalama kurallarını uygulama becerilerine etkisi. Mersin Üniversitesi Eğitim Fakültesi Dergisi, 9(3), 133-143.

Johnson, B. ve Christensen, L. (2014). Eğitim araştırmaları: Nicel, nitel ve karma yaklaşımlar (4. Bask1 ). S. B. Demir (Çev. Ed.), Ankara: Eğiten Kitap.

Kalfa, M. (2012). Türkçede noktalama. Ankara: Yarg1 Yayınevi.

Kara, E. (2010). Yazım, noktalama ve dil bilgisel becerileri kazandırma bakımından 6. 7. 8. sinıf ögrenci çalışma kitaplarının incelenmesi (Yayımlanmamış yüksek lisans tezi). Erzincan Üniversitesi Sosyal Bilimler Enstitüsü, Erzincan.

Karabuğa, H. (2011). Türkçe öğretmeni adaylarının yazılı anlatım çalışmalarında noktalama işaretlerini ve yazım kurallarını kullanabilme düzeyleri (Yayımlanmamıș yüksek lisans tezi). Abant İzzet Baysal Üniverstesi Sosyal Bilimler Enstitüsü, Bolu.

Karakoyun, M. E. (2010). İlköğretim 5. sınıf ögrrencilerine noktalama işaretlerinin öğretiminde işbirlikli öğrenme tekniklerinden jıgsawı'in akademik başarıya etkisi (Yayımlanmamış yüksek lisans tezi). Atatürk Üniversitesi Sosyal Bilimler Enstitüsü, Erzurum.

Kavcar, C., Oğuzkan, F. ve Aksoy, Ö. (2012). Yazılı ve sözlü anlatım (9. Bask1). Ankara: Anı Yayıncilik.

Kavcar, C., Oğuzkan, F. ve Sever, S. (2004). Türkçe ögretimi (7. Bask1). Ankara: Engin Yayınları.

Kerimoğlu, C. (2016). Dilbilgisi yazımı ve öğretimi (2. Bask1). Ankara: Pegem Akademi.

Kırbaş, B. (2010). Yeni Türkçe ders programına göre ilkögrretim yedinci sınıf ögrencilerinin yaratıcı yazma çalışmalarının yazım noktalama ve planlama açısından değerlendirilmesi (Yayımlanmamış yüksek lisans tezi). Atatürk Üniversitesi Sosyal Bilimler Enstitüsü, Erzurum.

Maden, A. (2013). Aktif ögrenme tekniklerinin ilköğretim 6. sinıf öğrencilerinin yazım ve noktalama kuralları başarısı ve derse karşı tutumlarına etkisi (Yayımlanmamış yüksek lisans tezi). Atatürk Üniversitesi Eğitim Bilimleri Enstitüsü, Erzurum.

MEB (2006). İlkögrretim Türkçe ögretim programı ve kılavuzu (6, 7, 8. Sinıflar). Ankara.

MEB (2015). Türkçe dersi öğretim programı (1-8. sinıflar için). Ankara.

Onan, B. (2006). Ses olgusunun denetlenebilirliği bağlamında dil becerilerinin geliştirilmesinde etkili olduğu düşünülen fonolojik yönlendiriciler: Noktalama işaretleri. TÜBAR-XX, 141-163.

Sever, E. ve Memiş, A. (2013). Süreç temelli yazma modellerinin ilkokul dördüncü sınıf öğrencilerinin yazım-noktalama becerisine ve yazma eğilimine etkisi. Karadeniz Sosyal Bilimler Dergisi, 5(9), 243- 259. 
Pajares, F. ve Valiante, G. (2006). Self-efficacy beliefs and motivation in writing development. A. C. Macarthur, S. Graham ve J. Fitzgerald (Yay. haz.). Handbook of Writing Research içinde (s. 158-170). New York: The Guilford Press.

Pekaz, K. (2007). İlkögretim sekizinci sınıf yazılı anlatımlarındaki ses olayları, noktalama, imlâ hataları ve anlatım bozukluklarının düzeltilmesinde ipucu ve geri bildirim teknikleri (Yayımlanmamış yüksek lisans tezi). Abant İzzet Baysal Üniversitesi Sosyal Bilimler Enstitüsü, Bolu.

TDK (2012). Yazım Kılavuzu. 27. Baskı, Ankara: Türk Dil Kurumu Yayınları.

Truss, L. (2003). Eats, shoots \& leaves: the zero tolerance approach to punctuation. London: Profile Books.

Uludağ, E. (2002). İlköğretim ikinci kademe öğrencilerinin yazım ve noktalama kurallarını uygulama beceri düzeyleri. Erzincan Ë̆itim Fakültesi Dergisi, 4(1), 97-114.

Yıldırım, A. ve Şimşek H. (2016). Sosyal bilimlerde nitel araştırma yöntemleri (10. Baskı). Ankara: Seçkin Yayıncılık.

\section{Extended Abstract}

\section{Introduction}

An important aspect of teaching writing skills is the ability to effectively teach punctuation rules and to have students practice these rules correctly (Bagci \& Karagul, 2013, p. 314). As part of this teaching process, proper use of punctuation marks is important in terms of ensuring the functioning of language, preserving the structure and meaning, and establishing a relationship between the writing language and speaking language (Maden, 2013).

Speaking is an action which requires some waiting time, short or long, between groups of words. While speaking, some words are stressed more to make them noticeable. Also, the face and hands can be used effectively in accordance with this purpose. With these, the meaning can become clearer. All these ways shape the talk. However, it is different in writing as also words need to be shaped. First, some space is left between the words. Secondly, punctuation marks are used in writing. Punctuation helps to write the text more easily and makes it understood clearly (Gordon, 1988, p.5). In other words, the value of sounds in speaking is provided with punctuation marks in writing. These marks prevent misunderstanding by organizing reading (Kavcar, Oğuzkan \& Aksoy, 2012, p. 42). At the same time, punctuation marks provide convenience for the reader to understand the text as the author means it. Punctuation marks also make it easier for the reader to maintain his/her interest in the text, separating the sentences which are the core units of meaning (Erten, 1959, p. 2; Kavcar, Oğuzkan \& Sever, 2004, p.84). Moreover, punctuation marks do also show the proper relations between independent sentences that ensure the formation of all written or verbal prose. (Dawkins, 1995).

Punctuation marks, when evaluated within the scope of teaching Turkish, may be perceived as a matter to develop writing skills. However, it is also related to reading skills as reading and writing are symmetrical skills. In literary genres closely linked with emotions and thoughts, especially poetry, it is better understood how important punctuation marks are in terms of reading/comprehension process (Onan, 2006). For this reason, students should be told how important the function of punctuation in reading is as well as in writing and activities should be organized related to this. As is known, achievements regarding the significance of punctuation marks in acquiring fluent reading skills are involved in teaching Turkish programme of 2015.

When the literature is reviewed, it is seen that there are studies on the use of punctuation marks and on the function of some methods, techniques and strategies in teaching punctuation marks (Ergin, 2009; Kara, 2010; Karakoyun, 2010; Kırbaş, 2010; Maden, 2013). However, there is no study revealing teachers' opinions who started to act as guides in the classroom with the advent of constructivist approach. 


\section{Method}

This research is a qualitative study to determine teachers' opinions on and approaches to teaching punctuation marks. 38 teachers participated in the research. The data of this study aiming to determine teachers' opinions and approaches on/to the process of teaching punctuation marks were collected through a semi-structured interview form. In the semistructured interview form, there are 6 open-ended questions to do this. Descriptive analysis method was used to analyze the data obtained from the study.

\section{Result and Discussion}

One of the results obtained from the study which aims to determine Turkish teachers' opinions and approaches on/to teaching punctuation marks is that Turkish teachers are aware of the importance and function of punctuation marks in basic skills to a large extent. As a result of this awareness, Turkish teachers are expected to be actively involved in teaching punctuation marks, to develop related activities and to evaluate/assess correctly. In this direction, techniques, methods and strategies that the teachers use were questioned. The result shows that $69.52 \%$ of Turkish teachers who participated in the study prefer direct instruction technique, $28.94 \%$ used question-answer method, and $26.31 \%$ benefitted from discovery learning technique. On the other hand, methods and techniques such as drama, brainstorming, and learning in a group which constructivist approach prescribes are used to a lesser extent. However, in literature, it has been found out that the use level of punctuation marks develop when methods and techniques prescribed by constructivist approach are applied. In the study conducted by Dölek and Hamzaday1 (2016), it was concluded that writing activities developed for peer interaction improve punctuation and writing skills. In another study by Maden (2013), it was found out that active learning techniques are more effective than traditional teaching methods on academic achievement of sixth graders in writing and punctuation rules and on their attitudes towards the course. In a similar way, Sever and Memiş (2013) reached the conclusion that the process-based writing model in which the student was centered had the effect of positively influencing the punctuation of students. From this point of view, it can be said that Turkish teachers should give more priority to the techniques and methods prescribed by the constructivist approach in which learners are active in the process of teaching punctuation marks. On the other hand, there are some studies showing that some techniques, which are a part of traditional teaching but still strong cognitively, improve how to use punctuation rules. To illustrate, the study conducted by Hamzadayı and Çetinkaya (2013) concluded that dictation practices developed the ability of students to apply the spelling and punctuation rules.

Another result obtained from the research is that semicolon and colon are the punctuation marks that students have the most difficulty to perceive and apply. On the other hand, question mark and the period are the easiest to understand and use for students according to the research. Teachers were undecided about students' understanding level of the comma. In the study conducted by Bağc1 (2011), the level of students to use the period and semicolon correctly shows parallelism with the teachers' remarks. Similar results were obtained in the master thesis by Karaboğa (2011). In this research, it was concluded that freshman students in the department of Turkish teaching used the period at a good level while they used the semicolon poorly. From this, it can be argued that problems related to punctuation marks in early periods continue in a similar way in the future.

Another result from the research is that teachers use assessment and evaluation tools such as text analysis, gap filling and multiple choice tests to a large extent to determine the level of students in terms of punctuation use. Nonetheless, it is also obvious that teachers do not prefer methods requiring low cognitive ability such as true-false activities.

On the other hand, when considering the function of punctuation marks in the development of reading skills, it is a striking fact that only $5.26 \%$ of the methods and techniques used to teach punctuation marks are related to reading, and it is not taken into consideration during the process of assessment and evaluation by the teachers. Accordingly, it can be said that the teachers are not interested in the assessment and evaluation of reading skills while 
determining the students' level of punctuation marks. In a study on this matter conducted by Baydık, Ergül and Kudret (2012), it was determined that the most common problem in students with reading difficulties is reading without paying attention to punctuation marks. It is also necessary for the teachers to give feedback to the students as a result of the assessment and evaluation. Pakaz (2007) reached the conclusion that using hints and feedback techniques has greatly reduced students' punctuation mistakes.

Finally, $60.52 \%$ of the Turkish teachers who participated in the research are of the opinion that activities in Turkish workbooks are not sufficient both in quality and quantity. On the other hand, $23.68 \%$ of the teachers think that activities are sufficient in quantity and quality. Therefore, it is necessary to increase the number and quality of activities related to teaching punctuation marks in Turkish workbooks and they should be reinforced in some ways. 